\title{
María Stegmayer
}

Universidad de Buenos Aires

mariastegmayer@gmail.com.

\section{Sobre las políticas del archivo: preguntas para una discusión}

\section{About archive policies: questions for discussion}

\section{Resumen}

El artículo se propone revisar y discutir algunos de los planteos referidos al vínculo entre archivo, democracia y Estado en el libro Anarchivismo. Tecnologías políticas del archivo, de Andrés Maximiliano Tello (La cebra, 2018) con el objetivo de esbozar una serie de preguntas a partir de las cuales la cuestión de las políticas del archivo o mejor, de la naturaleza de los vínculos entre poder arcóntico, máquina capitalista y subversión anarchivista, tal como los propone el libro, pueden ser abordados teniendo en cuenta algunas aristas singulares de los procesos de democratización social acontecidos en la historia reciente de algunos países latinoamericanos y en los cuales el Estado cumplió un rol fundamental.

Palabras clave: Archivo, Estado, política

\begin{abstract}
The article aims to review and discuss some of the issues related to the link between archive, democracy and State in the book Anarchivismo. Political Technologies of the Archive, by Andrés Maximiliano Tello (La Cebra, 2018) with the objective of outlining a series of questions from which the question of archive policies or better, of the nature of the links between arcontic power, capitalist machine and anarchist subversion, as proposed in the book, can be approached taking into account some singular edges of the processes of social democratization that occurred in the recent history of some Latin American countries and in which the State played a fundamental role.
\end{abstract}

Keywords: Archive, State, politics

\section{Introducción}

Las reflexiones que siguen fueron compartidas en ocasión de la presentación de Anarchivismo. Tecnologías políticas del archivo, de Andrés Maximiliano Tello (La cebra, 2018), que se realizó en Buenos Aires en en julio de 2019. No podíamos saber entonces lo que 


\section{María Stegmayer}

acontecería en Chile pocos meses después ${ }^{1}$. Si me atrevo a dejar mi intervención en esta extraña anterioridad, es decir, cuando Chile aún no había experimentado uno de los mayores -si no el mayor- estallido social de su historia, es con el deseo de que lo pronunciado entonces resuene ahora de una forma nueva.

Anarchivismo. Tecnologías políticas del archivo trae al ruedo no uno sino un gran conglomerado de problemas; cuestiones que nos confrontan con preguntas que apuntan a varios de los núcleos más acuciantes de nuestro tiempo. Se trata, además, de un libro que se mueve entre tiempos porque, para pensar lo que busca pensar, se sitúa en un punto de mira -o de escuchalevemente desplazado de su propio presente, lo que le permite elaborar su objeto sin reducirlo jamás a una actualidad rabiosa. Se dedica a hacerle justicia a su temporalidad compleja, más allá de los giros de última hora y avanza, por así decir, complicando un poco los tiempos. En este sentido, no solo estamos frente a un texto que mueve a pensar con él -que nos hace ir y venir sobre lo pensado- sino frente a uno cuya lectura nos depara una felicidad aún más esquiva: la de lo impensado, lo incalculable o lo imprevisto.

Si tuviera que resumir la apuesta del libro aludiendo a las voces que destacan en su recorrido, podría afirmar que Anarchivismo. Tecnologías políticas del archivo tiene un comienzo foucaultiano, donde se aborda lo que hizo Foucault con la noción de archivo a nivel epistemológico, metodológico y crítico para calibrar la gran transformación que opera la mirada foucaultiana sobre la categoría misma de archivo. Lo que nos lleva al siglo XIX, momento en que se consolida la archivística como ciencia positiva en su relación indisociable con la institución estatal y en sintonía, a la vez, con esa serie de instituciones reservadas a la memoria, registro y guarda de su patrimonio. El libro se detiene aquí, entre otras tecnologías políticas del archivo, en la creación de los Museos Nacionales, matrices organizativas, jerárquicas y perfectas sinécdoques de los archivos decimonónicos, imperiales y nacionalistas, que cimientan la "identidad eurocentrada de la civilización occidental” (Tello, 2018; 79). En ese sentido, señala Tello, “el

\footnotetext{
1 Iniciado por estudiantes secundarios que encabezaron una protesta contra al alza del pasaje del metro en Santiago con un llamado a saltar los molinetes al grito de "evadir, no pagar, otra forma de luchar", el estallido social comenzó el 18 de octubre de este año y fue creciendo y expandiéndose por distintas ciudades chilenas. La población salió y continuó manifestándose a pesar de la violenta represión del gobierno de Piñera. Se inició así -y continúa activo- un proceso de rebelión y resistencia popular con masivas movilizaciones callejeras y asambleas autoconvocadas que, más allá de la demanda puntual contra el aumento de transporte que encendió la mecha, se alzan contra 30 años de injusticia sistemática, desigualdad social, opresión patriarcal y autoritarismo jurídico experimentados como consecuencia del modelo neoliberal, hegemónico en Chile desde los tiempos de la dictadura de Pinochet.
} 


\section{María Stegmayer}

museo no es solo una muestra privilegiada de los regímenes sensoriales del archivo sino que además, en ese momento histórico, es un prototipo en que el archivo manifiesta su carácter de máquina social del archivo" (Tello, 2018; 79). Más tarde, durante el paso del siglo XIX al siglo $\mathrm{XX}$, los regímenes sensoriales de la máquina se verán trastocados por nuevas tecnologías, que producirán un despliegue inédito sobre la superficie del cuerpo social para poner en el centro de la escena, y tal como anticiparía Walter Benjamin, la cuestión de la reproductibilidad técnica de la obra de arte, y más allá del arte, el problema más amplio de la mediatización de las sociedades y el lugar de los nuevos medios audio-visuales de comunicación de masas. Podría decirse que así como Anarchivismo parte y sitúa su indagación retomando mucho del primer Foucault (el de la Arqueología del saber), un corazón derridiano cobija el trabajo de Tello sobre la compleja red de significantes - escritura, huella, memoria, soporte, superficie de registro, iterabilidad, suplemento, espectralidad de las marcas- ligados al archivo y, a partir de los cuales, las nociones clásicas y metafísicas de representación, identidad, reproducción, violencia, totalidad y origen van a ser problematizadas, de Platón a Levy-Strauss; de Freud y su famosa pizarra mágica -metáfora del aparato psíquico y de una escritura inconsciente- a la escena de escritura que protagoniza el propio Derrida frente a su computadora Macintosh. Las tesis derridianas que retoma el libro permiten afirmar que la superficie de inscripción es indisociable de la inscripción en tanto tal y de las condiciones materiales en que ésta se genera. Si no hay formación social cuyas inscripciones cualquier inscripción durable de un signo sobre la superficie de un cuerpo- no funcione como escritura en el sentido derridiano es decir, una violencia que entraña el diferimiento irremediable de huellas siempre ya divididas de sí mismas en una escisión sin origen presentificable o restituíble, esta concepción de la escritura como différance permite "vislumbrar el funcionamiento de la máquina social del archivo y sus múltiples tecnologías de registro, cuyas operaciones recorren de modo heterogéneo el conjunto de la superficie social" (Tello, 2018; 122). Sin embargo, en este punto aparece una cuestión que, al decir del autor de Anarchivismo. Tecnologías políticas del archivo, la óptica de Derrida no permitiría enfocar: la cuestión de la diferencia y la ruptura entre los distintos regímenes de inscripción ${ }^{2}$ :

\footnotetext{
${ }^{2}$ Deleuze y Guattari plantean de modo conceptual (y no evolutivo) tres tipos de máquinas o formaciones sociales que se inscriben en un mismo plano de inmanencia: la máquina territorial o nómada; la máquina del Estado y la máquina capitalista. (Deleuze y Guattari, 2002; 145-279).
} 


\section{María Stegmayer}

"La cisura en los regímenes de inscripción organizados sobre la superficie social se refiere (...) a la diferencia entre la máquina primitiva y la máquina imperial, es decir (...) entre la codificación territorial grupal y una sobrecodificación estatal, que transforma la condición de la escritura en sentido general. Derrida no se detiene en este problema que, en cambio, resulta fundamental para el análisis de los regímenes de inscripción planteados por el materialismo histórico-maquínico" (Tello, 2018; 23)”.

Así emerge el tercer momento que transita el libro: el deleuziano-guattariano. Aunque se trata de una presencia que impregna todo el desarrollo, me arriesgaría a afirmar que con el materialismo histórico-maquínico de Deleuze-Guattari se prepara lo que será la dimensión propositiva del texto, en combinación con una especie de bajo continuo rancieriano al que luego me referiré de modo más extenso. Pero creo que en el corazón del libro encontramos ya algunas aristas significativas de la discusión que me interesaría plantear. Se trata de la cuestión del vínculo entre poder arcóntico estatal como un poder y una violencia de lo Uno, que sobrecodifica las inscripciones y las máquinas de guerra nómades planteadas, por el contrario, bajo el signo de la multiplicidad y la heterogeneidad. Cito a Tello:

“Cuando Deleuze y Guattari definen la máquina nómada, señalan que esta se refiere no solo a una máquina de guerra que es exterior a la captura estatal $^{3}$, sino que además da lugar a un tipo de ocupación y producción de otro-espacio tiempo" $(2018 ; 133)$

De modo sintético y enfático, se advierte: "Toda máquina nómada podría ser leída desde este prisma: un esfuerzo por mantener la multiplicidad que difiere de la unificación estatal" (Tello, 2018; 131). En términos analíticos, el argumento se ocupa de precisar que el campo maquínico es el de la coexistencia de las máquinas y sus potencias y que las máquinas nómadas pueden o bien conjurar la lógica estatal, o bien quedar capturadas en ella. Lo sintomático es que el énfasis en ese campo de coexistencia exterior (aún si se dice en una nota a pie que hay

\footnotetext{
${ }^{3}$ El subrayado es mío.
} 


\section{María Stegmayer}

coexistencia exterior de las formaciones, pero también coexistencia intrínseca de los procesos maquínicos ${ }^{4}$ ) consigue dejar en un segundo plano la ambivalencia intrínseca al sostener siempre la lógica de la conjuración nómada versus la captura estatal. Esta oposición, a pesar de las salvedades, permanece. De la máquina estatal solo se enfatiza una y otra vez el poder de captura, unificador. Se afirma entonces que mientras "la máquina del Estado coexiste efectivamente con la máquina capitalista en distintas formas, las máquinas primitivas conjuran a las estatales o pueden también ser capturadas por estas últimas" (Tello, 2018;13). Como sea, estas parecen ser las alternativas.

\section{Preguntas para una discusión}

Estos son solo algunos de los autores que Anarchivismo convoca a la conversación. Dentro de este conjunto de voces, quisiera detenerme un poco en el lugar de la de Rancière porque me permite dar una pequeña discusión y plantear algunas cuestiones que tienen que ver especificamente con las políticas del archivo en América Latina: me refiero a la potencia anarchivista que Tello nos invita a pensar y que se declina a la vez como problema filosófico y como práctica política. Para decirlo con Rancière, la cuestión del reparto sensible de los cuerpos y de los los corpus, tal como agrega el autor de Anarchivismo. Me parecía que, efectivamente, es el Rancière (2009) de "la partición de lo sensible" la voz que más puede escucharse en la posición política -el anarchivismo como subversión del orden policial de los cuerpos y de los corpus- argumentada en el libro. Mi inquietud surge entonces a partir de aquí. El anarchivismo se concibe como un movimiento subterráneo, esa potencia disruptiva que interrumpe las lógicas policiales, identitarias e instrumentales que sancionan jerarquías, lugares y funciones en un espacio social pretendidamente transparente.

De modo que un movimiento anarchivista es eso que sucede cuando se perturba o se conmueve, se pone a temblar o se inquieta, una cierta zona del orden en tanto tal, entendiendo por orden una determinada manera de distribución y aparición pública de los cuerpos, de su visibilidad y audibilidad, de su contabilidad efectiva y de todas las modalidades de su registro, inseparables - así lo muestra el libro- de lo anterior. Podría decirse, desde esta perspectiva, que estamos frente a un acontecimiento político - que hay política, afirmaría Ranciere- cuando esta

\footnotetext{
${ }^{4}$ El subrayado es mío.
} 


\section{María Stegmayer}

oleada disruptiva sacude los puntos de fijeza y coherencia interna del orden vigente. El anarchivismo es la pesadilla de todo orden porque arremete y altera la pretendida eternidad, inteligibilidad o transparencia de sus fundamentos últimos.

Ahora bien ¿no subyace a la concepción rancieriana del acontecimiento político como movimiento interruptivo del orden policial una especie de fascinación por el momento insurreccional, al punto de identificar la política exclusivamente con esa escena de ruptura, de discontinuidad? ¿No lleva esto a una suerte de romantización del acontecimiento anárquico impidiendo pensar otras valencias de la política por fuera de la lógica acontecimiental del desorden así delineada ${ }^{5}$ ? Creo que la potencia anarchivante que rastrea el libro le debe mucho a esta escena disruptiva en la cual un cuerpo colectivo interrumpe la "normalidad" del lenguaje -y con ello de los afectos y de la sensibilidades colectivas disponibles- para producir las condiciones de una nueva escena enunciativa: un movimiento de subjetivación política que hace aparecer el filo opresivo y represivo de un poder hasta entonces invisibilizado en su forma de sujetar los cuerpos, domesticar las voces, interpretar y sancionar la legalidad de los corpus. Este momento de insurrección suele ubicar, como su contrafigura privilegiada, a la captura: la contra-escena en que las lógicas institucionales se tragan las energías más genuinas y espontáneas de la "revuelta"; una especie de inevitable agotamiento que marca el paso a instancias más grises y contaminadas sin duda menos fascinantes- de construcción política, de negociación política y de arduas confrontaciones que ya no tienen por contraparte un bloque unificado de Poder constituido sino instancias parciales e internamente diferenciadas que se plantean la tarea de construir mediaciones, frágiles continuidades e inestables compromisos.

Me interesaba pensar entonces si el anarchivismo puede ser algo diferente de esa máquina de guerra nómade que interrumpe el orden e insubordina los signos del El Poder constituido. Pensar, usando los términos de Rancière, la diferencia interna y la complejidad de lo que el autor de El desacuerdo llama los órdenes policiales (¿Son todos equidistantes? Claro que no, se apura a

\footnotetext{
${ }^{5}$ Afirma Rancière en el debate posterior a la Conferencia dictada en ocasión del recibimiento del Honoris Causa por la Universidad Nacional de San Martín en Argentina en el año 2014: "Siempre hubo poder y hay muchas formas de poder que no son políticas: el poder del jefe, el del maestro, el del patrón, el del amo... Son poderes privados, poderes de relación de autoridad que funcionan socialmente. Lo que me interesa es pensar cómo se puede fundar de modo general la idea misma de lo político. Y lo que me interesa verdaderamente es el modo en que el principio democrático funciona en sí mismo siempre como un desafío con respecto al principio estatal. Porque el principio estatal, a pesar de todo, siempre funcionó como un principio de confiscación y privatización del poder colectivo".
} 


\section{María Stegmayer}

contestar Rancière, pero ¿cómo y con qué categorías y lógicas analíticas pensamos sus diferencias?) ¿O cómo pensar la potencia -volviendo a los términos de Deleuze y Guattari- de la máquina nómada anarchivista más allá, o más acá, de la alternativa entre conjuro y captura? ¿Cómo responder desde la lógica acontecimiental del estallido a la construcción de institucionalidad democrática? ¿Cómo pensar, dicho en otros términos, una continuidad anarchivante al perder el brillo de la radical discontinuidad se vuelva más bien opaca? ¿Qué tipo de desajuste en las memorias y los tiempos, en los cuerpos y los corpus, se volvería visible de ese modo? ¿Cómo articular estas preguntas desde América Latina, teniendo en cuenta las violencias que atraviesan su historia y su presente y la preocupante persistencia en nuestros países de fuerzas archiviolíticas - diría Derrida- que interrumpen toda fijación, toda consolidación, toda sedimentación, toda pulsión vital de conservación y, en el límite toda memoria y todo archivo democrático? ¿Cómo defender la conservación activa de nuestro precario "archivo democrático" en un momento en que se pretende una vez más desestabilizarlo, destruirlo, borrarlo, invocando muchas veces para ello la lengua de la revuelta y de la insurrección?

¿Cómo disputar los sentidos democráticos de la revuelta política a partir de esta relación siempre ambivalente, siempre tensa y coyuntural, entre movimiento archivante de identificación e irrupción anarchivista desidentificante? ¿Se puede reducir esta relación a la lógica de la captura de uno por el otro? ¿Habría alguna ambivalencia constitutiva en el movimiento anarchivante capaz de complicar su relación unívoca con la emancipación? ¿Cómo pensar en términos políticos la deseabilidad de ciertas continuidades sin hacer de la discontinuidad un fetiche independiente de las coyunturas? Por ejemplo, si pensamos el archivo en su acople con la máquina estatal y con la máquina capitalista en su inflexión neoliberal actual, ¿no habría que decir también que la máquina estatal no siempre se acopla de modo perfecto, liso o sin resto a la máquina capitalista? ¿No hay un exceso opaco y no codificable en los archivos estatales latinoamericanos, una memoria política de lo que permanece pendiente, un resto utópico que habría que poder resguardar en un momento en el que el corte, la destrucción y la voluntad de borramiento de una cierta concepción del Estado -en su capacidad de activar y liderar procesos de democratización social sustantivos- está en marcha y se constituye como la regla? ¿No constituye ese exceso no sobrecodificado en el Estado una reserva democrática capaz de activarse en momentos de peligro y cuya permanencia siempre amenazada es nuestra responsabilidad? 
Cuando hablamos de los archivos de la precaria máquina estatal en países periféricos como los nuestros ¿no resulta crucial atender a la centralidad que ha tenido el Estado en los procesos de democratización que hoy se busca desmontar ${ }^{6}$ ? Esto me recuerda el título de un libro de Miguel Abensour (1998), La Democracia contra el Estado, que no puedo pronunciar sin cierta incomodidad. Nos obliga a calibrar el peligro que supone asumir esa oposición ${ }^{7}$. ¿Podemos hoy, nosotros, acá, en América Latina suscribirla por completo? ¿A qué concepción del Estado nos limita ${ }^{8}$ ?Cómo pensar la democracia con, desde y/o junto al Estado? ¿No será necesario atender a la complejidad situada de los procesos histórico políticos aun cuando estos parezcan contradecir a priori teóricos demasiado apresurados en su afán de proveer un paradigma crítico poco propenso a pensar zonas más grises, complejas y contaminadas de la política? En esta línea, señala Emmauel Biset:

"Dicho esto, se entiende que se trata de una apuesta por un pensamiento que atienda a la política como los modos de constitución y configuración de un mundo. Donde no resulta necesario partir de una

\footnotetext{
${ }^{6}$ No hace mucho Eduardo Rinesi se refería a la cuestión del Estado y los derechos en relación a otro tema que no deja de vincularse al archivo: la universidad. Rinesi se refería en su intervención -vuelta artículo en un libro que compiló los textos preparados para un Coloquio sobre el tema realizado en Chile- a la cuestión de los derechos. "El derecho, enfatizaba, es ese estado intermedio entre el "ser de las cosas" y su "deber ser", entre la descripción y la prescripción y es justo en ese lugar intermedio en el que se ubica que recoge toda su fuerza y su interés. Es en ese sentido, continuaba -y aquí lo parafraseo- que debe medirse el importante proceso de democratización de varias de nuestras sociedades sudamericanas ocurrido durante los primeros tres lustros del siglo XXI (...). Es en este clima general de ideas, promovido por la entonación democratizante de muchas de las políticas públicas impulsadas desde la cima de los aparatos de nuestros Estados (...) que la Universidad ha podido ser pensada, también, como un derecho humano universal. (2018; 487) ¿No puede pensarse entonces que el Estado resiste la sobrecodificación que se le atribuye en tanto poder arcóntico? ¿No se vuelve aquí el Estado sede de un movimiento anarchivante que no viene de ningún afuera? ¿No es una fuerza intempestiva aquí el Estado frente a la máquina capitalista productora de desigualdad o frente a un modo limitado de comprender el lazo entre democracia y Estado? Ver: Rinesi, Eduardo (2018). "De filósofos y zapateros (Dos notas sobre la idea de Universidad como derecho)" en La universidad (im)posible. Thayer, W., Collingwood-Selby, E., Estupiñán Serrano, M.L., rodríguez feire, r. (Editores), Santiago de Chile. Ediciones Macul.

7 En esta misma línea está también el libro, anterior al de Abensour, de Pierre Clastres (1978). La sociedad contra el Estado, Caracas. Monteávila, que sí aparece citado en Anarchivismo. Tecnología política del archivo.

${ }^{8}$ En el debate posterior a la Conferencia dictada en ocasión del recibimiento del Honoris Causa por la Universidad Nacional de San Martín en Argentina en el año 2014, Rancière precisaba que desde su punto de vista "la democracia sería de ese modo lo ingobernable mismo en su manifestación, es decir, la acción igualitaria que desordena el reparto jerárquico de lugares, papeles sociales y funciones, abriendo el campo de lo posible y ampliando las definiciones de la vida común" Afirmó, ante un auditorio muy interesado en los escenarios de los entonces gobiernos progresistas de la región (Venezuela, Argentina, Ecuador, Uruguay, etc.): "No hay Estado democrático". Es decir, no hay traducción institucional posible de este fondo disruptivo, expansivo, de la política. En todo caso pueden darse algunos efectos, en términos de libertades o derechos. Pero "la democracia no se identifica con una forma de Estado, sino que designa una dinámica autónoma con respecto a los lugares, a los tiempos, a la agenda estatal”.
} 


\section{María Stegmayer}

definición dada de política para encontrar su vínculo necesario con la ontología, sino mostrar que una pregunta sólo da lugar a pensar esos dos procesos en su inmersión en un mundo, en su contaminación con el mismo. Esto permite señalar, primero, que la calificación de político de un pensamiento se produce desde su contaminación con procesos políticos específicos, siempre múltiples, pero, segundo, que la misma posibilidad de apertura de un pensamiento conlleva una dimensión nominativa, es decir, calificar de políticas dimensiones del mundo antes excluidas" (Biset, 2014;147).

Surge entonces otra pregunta ¿no pueden los Estados encarnar también en ciertas circunstancias una singular potencia anarchivista? ¿Ese poder anarchivante -su potencia democratizadora- no habría que pensarla también al interior, en los intersticios de una institucionalidad estatal no unificadora sino porosa, pletórica de heterogeneidades y temporalidades disyuntas? ¿Cómo pensar una lógica que no asocie el estado solamente a la captura de las energías democráticas que crecerían espontáneas y silvestres en otra parte? ¿Cómo concebir un pensamiento abierto a las contaminaciones que pueden producirse entre una máquina estatal, que no funciona en bloque ni de acuerdo a una sola lógica, y una serie de movimientos que lejos de contraponerse puedan acoplarse productivamente?

\section{A modo de cierre}

La larga serie de preguntas esbozadas en lo anterior plantean la necesidad teórica y política de abrirnos a un pensamiento-otro sobre el Estado, uno capaz de producir otros entrelazamientos en el corpus de cuestiones que informa la discusión sobre el vínculo entre Estado y democracia, para desordenar y subvertir ese dossier, la versión dominante -y en gran medida eurocentrada- de ese gran y complejo archivo. Cito de nuevo y extensamente a Biset quien sintetiza varios de los puntos planteados hasta aquí, cuando propone que:

“Abrir la dimensión ontológica del Estado supone, no sólo atender a su dimensión instituyente, sino dislocar una concepción de Estado como 


\section{María Stegmayer}

entidad meramente represiva. El esfuerzo de un pensamiento tal se dirige a romper con la circularidad de poder-libertad que hace del Estado un todo caracterizado por la represión de subjetividades que lo exceden. De hecho, un planteo recurrente es aquel según el cual el Estado surge para regular una exterioridad conflictiva o indómita. Posiblemente allí donde adquiere mayor radicalidad esta perspectiva, es en la noción de 'deseo' como índice de la subjetividad moderna, desde el estatuto conflictivo al que conduce lo infinito del deseo en Hobbes hasta las máquinas deseantes deleuzeanas, el Estado pasa a funcionar como orden, represión o captura. Frente a ello, se trata de mostrar el modo en que el Estado configura cierta subjetividad, o incluso, cómo configura un cierto modo de desear. Lo que lleva a indagar sobre cuál es la singularidad del modo de configuración estatal del mundo. Pues se trata de pensar el Estado como instancia productora de subjetividad, o diría, como instancia que abre posibilidades, potencialidades. El Estado como un conjunto de dimensiones que se pliegan entre sí sin un sentido unívoco dando lugar a procesos constitucionales, es decir, a una dinámica nunca plenamente coincidente entre lo constituyente y lo constituido. Esta dinámica hace de todo Estado un proceso en sí mismo contradictorio, cuya orientación política, y la posibilidad de su calificación como derecha o izquierda, sólo puede darse atendiendo a esa multiplicidad. Lo que implica, en última instancia, que no hay un Estado-uno que pueda ser definido en su totalidad por una orientación de izquierda o derecha" (Biset, 2014; 149).

Por último, pensaba que si nos referimos a las relaciones entre Estado, democracia y archivo, este problema se puede ligar en Argentina al vínculo entre el archivo y la política de derechos humanos que impulsa la búsqueda y restitución de los restos de detenidos desaparecidos de le última dictadura cívico militar a sus familias que aún los buscan. Recordaba, a propósito de esto, una escena muy fuerte, muy conmovedora, del libro autobiográfico de Marta Dillon, Aparecida (2015), donde ella, que está en España en un festival de cine con su mujer recibe, en ese momento totalmente inesperado y después de muchos años de buscar sin éxito el cuerpo de su 


\section{María Stegmayer}

madre desaparecida, una llamada del equipo de Antropología Forense que le comunica que hallaron algunos huesos, que finalmente identificaron esas piezas exhumadas con los datos que figuran en el archivo de la institución, que tienen un... fémur. Este es un punto muy dramático, un punto político de entrelazamiento entre el cuerpo, el corpus, el archivo y el Estado. Y tomo este ejemplo porque en este caso el archivo aloja una promesa democrática que en la historia reciente de Argentina no puede ser pensada al margen de un Estado que impulsó políticas concretas en relación a los reclamos de Memoria, Verdad y Justicia. Me animo entonces a decir que no podemos pensar nuestras democracias contra el Estado, y retener solo el momento anárquico que la palabra anarchivismo deja escuchar, a veces, asordinando otros acordes necesarios. Lo que significa, retomo acá los planteos de Biset, que el Estado si bien no como única institución, es uno de los lugares para comprender el cómo de la configuración del mundo moderno, y que dicha comprensión requiere de un desplazamiento en la concepción del Estado capaz de pensar sus complejidades, ambivalencias, tensiones y aperturas, en otros términos, su ser más o menos hospitalario para las políticas democráticas, es decir su capacidad de limitarlas pero también de impulsarlas activamente, lo que las vuelve no instancias necerariamente contrarias sino, muchas veces, inseparables de los resortes e instrumentos políticos que habilita el Estado. Este movimiento que resiste concepciones simples o reduccionistas de la estatalidad y que no renuncia a pensarla a partir de experiencias políticas e histórico concretas resulta "central puesto que en diversos planteos contemporáneos el Estado sólo se entiende como un ente solidificado, como una institución fija y estable (Biset. 2014: 149)" como potencia de captura y unificación que impide pensar otras de sus valencias ético-políticas capaces de pensarlo en su frágil complicidad con una política que active procesos de democratización en contextos de creciente desigualdad.

Nos toca pensar entonces la complejidad de una política democrática capaz de hacerle lugar a al deseo de preservar, activar y politizar los archivos estatales democráticos en América Latina: el deseo de proteger su fragilidad y de garantizar su compromiso con la verdad y la justicia. En otras palabras, la necesidad de velar por la continuidad y la permanencia de los archivos allí donde son un componente crucial de nuestra memoria democrática y por ello de nuestro futuro democrático. Esa permanencia, la frágil y precaria continuidad de un "derecho al archivo" bajo la ofensiva neoliberal actual no deja de estar amenazada. 


\section{María Stegmayer}

\section{Bibliografía}

Barnouw, Erik. (2005) El Documental: historia y estilo. Barcelona: Gedisa

Abensour, Miguel. (1998). La Democracia contra el Estado. Buenos Aires: Colihue.

Biset, Emmanuel. (2104). "Hacia una ontología política del Estado", en Utopía y Praxis

Latinoamericana. Año 19, No. 66 (2014), pp. 137 - 152.

Clastres, Pierre. (1978). La sociedad contra el Estado, Caracas: Monteávila.

Deleuze, Gilles. y Guattari, Felix. (2002). El Anti-Edipo. Capitalismo y esquizofrenia, Valencia:

Pretextos.

Derrida, Jacques. (1997). Mal de archivo. Una impresión freudiana. Madrid: Trotta.

Derrida, Jacques. (1989). "Freud y la escena de la escritura", en La escritura y la diferencia.

Barcelona: Anthropos.

Dillon, Marta. (2015). Aparecida. Buenos Aires: Sudamericana.

Rancière, Jacques. (1998). El desacuerdo. Política y filosofía. Buenos Aires: Nueva Visión.

Rancière, Jacques. (2009). El reparto de lo sensible. Estética y política. Santiago de Chile: LOM

Rinesi, Eduardo (2018). "De filósofos y zapateros (Dos notas sobre la idea de Universidad como derecho)" en La universidad (im)posible. Thayer, W., Collingwood-Selby, E., Estupiñán Serrano, M.L., rodríguez feire, r. (Editores), Santiago de Chile: Ediciones Macul.

Tello, Andrés. (2018). Anarchivismo. Tecnologías políticas del archivo. Buenos Aires: La Cebra. 